\title{
Practical Synthesis of Iboxamycin, a Potent Antibiotic Candidate, in Amounts Suitable for Studies in Animal Infection Models
}

\author{
Jeremy D. Mason, Daniel W. Terwilliger, Aditya R. Pote, and Andrew G. Myers*
}

\begin{abstract}
A gram-scale synthesis of iboxamycin, an antibiotic candidate bearing a fused bicyclic amino acid residue, is presented. A pivotal transformation in the route involves an intramolecular hydrosilylation-oxidation sequence to set the ring-fusion stereocenters of the bicyclic scaffold. Other notable features of the synthesis include a high-yielding, highly diastereoselective alkylation of a pseudoephenamine amide, a convergent $\mathrm{sp}^{3}-\mathrm{sp}^{2}$ Negishi coupling, and a one-pot transacetalization-reduction reaction to form the target compound's oxepane ring. Implementation of this synthetic strategy has provided ample quantities of iboxamycin
\end{abstract} to allow for its in vivo profiling in murine models of infection.

\section{INTRODUCTION AND BACKGROUND}

The lincosamide antibiotics are orally available, nontoxic, bacteriostatic agents that act to inhibit translation by binding to the $23 \mathrm{~S}$ subunit of the bacterial ribosome, near the peptidyl transferase center. ${ }^{1}$ The founding member of the class, lincomycin (1, Figure 1), was isolated in 1963 by scientists at The Upjohn Company from a culture of the soil bacterium Streptomyces lincolnensis. ${ }^{2}$ Lincomycin quickly gained FDA approval (1964) for the treatment of infections caused by Gram-positive pathogens. The semisynthetic derivative clindamycin (2), prepared by selective, stereoinvertive deoxychlorination of lincomycin at $\mathrm{C} 7$, showed improved in vitro and in vivo activity relative to lincomycin and was approved for use in humans in $1970 .^{3}$ In addition to its antibacterial properties, clindamycin can also be used for the treatment of $P$. falciparum malaria. ${ }^{4}$ Clindamycin is commonly used to treat dental infections ${ }^{5}$ and osteomyelitis, ${ }^{6}$ and in topical form as an anti-acne agent, ${ }^{7}$ but its widespread oral and parenteral administration (the latter in the form of the 2-phosphate ester prodrug) is contraindicated due to the risk of promotion of secondary Clostridioides difficile infections. ${ }^{8}$ In addition, as with most antibiotics in use for decades, multiple bacterial resistance genes have evolved and are now widespread in bacteria within the community. ${ }^{9}$ In spite of much effort, no new members of the lincosamide class have advanced to the clinic in the past five decades, which has possibly promoted a selfsustaining perception that the class has little to offer in terms of future antibiotics. ${ }^{10}$

Over a period of more than 5 years, our laboratory has been involved in the continuous development of new methodology for the chemical synthesis of novel lincosamides in a search for next-generation antibiotic candidates that (1) are effective against current multi-drug resistant clinical isolates and (2) have the potential to overcome the $C$. difficile liability of clindamycin. In his $\mathrm{PhD}$ research, Dr. Matthew Mitcheltree pioneered new chemistry permitting fully synthetic construction of novel lincosamides with modified aminooctose subunits and initiated the discovery and construction of novel bicyclic scaffolds to replace the 4'- $n$-propyl hygric acid residue of lincomycin and clindamycin. ${ }^{11}$ The $\mathrm{PhD}$ thesis research of Drs. Katherine Silvestre and Ioana Moga permitted

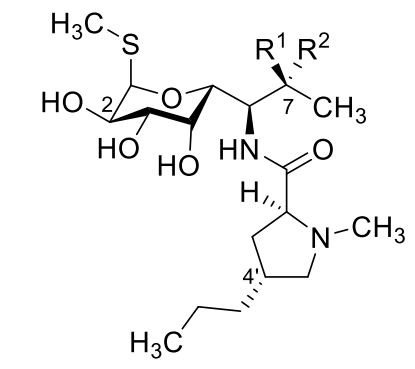

Lincomycin (1) $\mathrm{R}^{1}=\mathrm{H}, \mathrm{R}^{2}=\mathrm{OH}$

Clindamycin (2) $\mathrm{R}^{1}=\mathrm{Cl}, \mathrm{R}^{2}=\mathrm{H}$

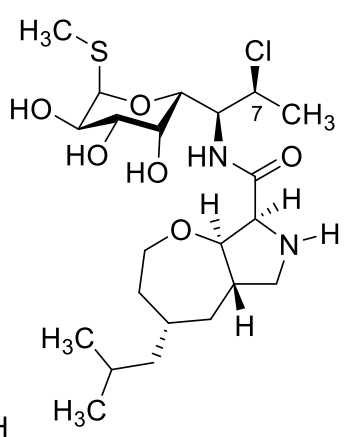

Iboxamycin (3)

Figure 1. Structures of lincomycin (1), clindamycin (2), and the novel bicyclic analog iboxamycin (3), whose gram-scale synthesis is outlined herein.

an extensive investigation of scaffold substituents, resulting in a large expansion of our synthetic lincosamide library (currently $>500$ members), with $>80 \%$ of the analogs having demonstrable antibacterial activity. ${ }^{12}$ Dr. Katherine Silvestre discovered the molecule which bears the name iboxamycin (3), whose remarkable antibacterial effects, ribosomal-binding studies, and promise in animal infection models will be detailed elsewhere in a parallel submission for publication. ${ }^{13}$ The original synthetic route to iboxamycin (3) provided quantities of material that were sufficient for extensive minimum inhibitory concentration assays against various bacterial strains ( $\sim 50 \mathrm{mg}$, isolated as its formic acid salt after purification by RP-HPLC), but the sequence was lengthy and laborious as it had been designed as a discovery engine, not for efficient synthesis of iboxamycin (3) specifically. Considerable efforts were made to improve and substantially scale the discovery route so as to provide the greater quantities of iboxamycin that would be necessary to explore its efficacy in animal infection models. However, this work ultimately only reinforced the sense that an entirely new and different sequence would have to be developed to produce iboxamycin. Here, we present that route, its development and refinement, and implementation to produce $>1 \mathrm{~g}$ of iboxamycin (3), an amount more than sufficient to support ongoing murine infection studies. Should it be warranted, we believe the route presented could provide the basis of a manufacturing route. 
Scheme 1. Retrosynthetic Analysis of the $N$-Protected Amino Acid Component 4<smiles>CC(C)C[C@@H]1CCO[C@H]2C(C(=O)O)N(C(=O)OCc3ccccc3)C[C@H]2C1</smiles><smiles>[R]OC(=O)N1C[C@H](C[C@@H](CC(C)C)CC2OCCO2)[C@H](O)[C@H](CO)N1C(=O)OCc1ccccc1</smiles>

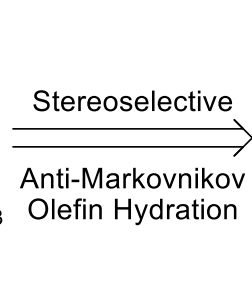<smiles>CC(C)C[C@H](CC1=C[C@@H](CO)N(C(=O)OCc2ccccc2)C1)CC1OCCO1</smiles>
Negishi

Coupling<smiles>CC#C[Ga]C[C@@H](CC(C)C)CC1OCCO1</smiles><smiles>CC(C)C[C@H](CC1OCCO1)C(=O)N(C)[C@H](c1ccccc1)[C@H](O)c1ccccc1</smiles><smiles>CN(C(=O)CCC1OCCO1)[C@@H](c1ccccc1)[C@H](O)c1ccccc1</smiles>

\section{RESULTS AND DISCUSSION}

Retrosynthetic Analysis. Simplification of the novel bicyclic amino acid component of iboxamycin (in $\mathrm{N}-\mathrm{Cbz}$ protected form, subtarget 4) was reimagined along the lines presented in the retrosynthetic analysis shown in Scheme 1. Our initial disconnection targeted the oxepane ring, which we proposed might be constructed in a reductive cyclization reaction of the dihydroxy acetal $\mathbf{5}$. This, in turn, was considered to arise from an anti-Markovnikov, suprafacial hydration of the alkene 6, which we anticipated would require methodological development, but was considered strategic because it would set the stereochemistry of positions $3^{\prime}$ and 4 ' in one operation. Disconnection of $\mathbf{6}$ by targeting the alkene appendage using a Negishi coupling ${ }^{14}$ transform gave rise to the known vinyl triflate $7^{15}$ and the elaborated organozinc reagent $\mathbf{8}$ as starting materials. The latter was envisioned to arise from a straightforward sequence initiated in the synthetic direction by an asymmetric alkylation reaction of $(R, R)$-pseudoephenamide $\mathbf{1 0}$ toward $\alpha$-substituted amide 9 , as depicted. ${ }^{16}$

Implementation of an Asymmetric Alkylation Protocol to Construct the Direct Precursor to the Elaborated Organozinc Reagent 8. By modifying literature protocols, we were able to prepare the carboxylic acid 12 in multidecagram quantities (Scheme 2). ${ }^{17}$ Specifically, we learned that formation of the Grignard reagent from the commercially available alkyl bromide $\mathbf{1 1}$ was best achieved by activation of the magnesium metal turnings using $1 \mathrm{~mol} \%$ of diisobutylaluminum hydride according to the procedure of Tilstam and Weinmann. ${ }^{18}$ After sparging with carbon dioxide with care to control the exotherm, the carboxylic acid $\mathbf{1 2}$ was obtained as an amorphous white solid after extractive isolation $(35.7 \mathrm{~g}$, $72 \%)$. Amide bond formation between 12 and $(R, R)$ pseudoephenamine $(\mathbf{1 3})^{19}$ by mixed anhydride activation of 12 with pivaloyl chloride provided pseudoephenamide $\mathbf{1 0}$ as white needles after extractive isolation and recrystallization from 1:1 ethyl acetate-hexanes $(56.0 \mathrm{~g}$, first crop, mp 111$112{ }^{\circ} \mathrm{C}, 8.0 \mathrm{~g}$, second crop, $84 \%$ total). An additional $3.3 \mathrm{~g}$ of product $(4 \%$, total yield $88 \%$ ) was obtained by flash chromatography of the residue obtained from concentration of the mother liquors using acetone-hexanes as eluent.

We found that neither isobutyl iodide nor isobutyl triflate were sufficiently reactive as substrates for highyielding alkylation of the lithium enolate of pseudoephenamide 10, but methallyl bromide provided excellent results.
Thus, formation of the lithium enolate using the standard protocol ( $\mathrm{LiCl}, 6$ equiv, LDA, 2.1 equiv, tetrahydrofuran (THF), $\left.-78{ }^{\circ} \mathrm{C} \rightarrow 0{ }^{\circ} \mathrm{C} \rightarrow 23{ }^{\circ} \mathrm{C} \rightarrow 0{ }^{\circ} \mathrm{C}\right)$ followed by addition of methallyl bromide ( 2 equiv) at $0{ }^{\circ} \mathrm{C}$ provided the alkylation product 14 as a colorless gum in $92 \%$ yield after extractive isolation and purification by flash column chromatography. ${ }^{16}$ The product was shown to have a dr of $>19: 1$ by using the oxazolinium triflate method. ${ }^{20}$

Scheme 2. Synthesis of Alkyl Iodide 16

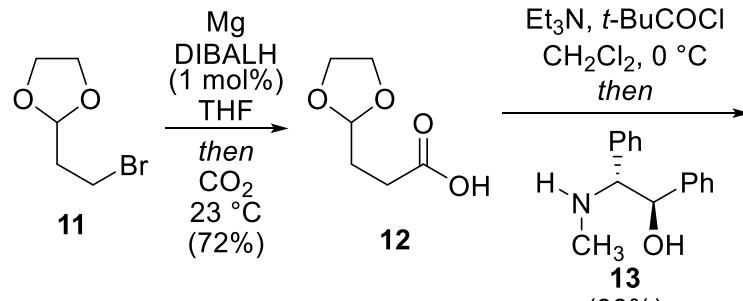

$(88 \%)$
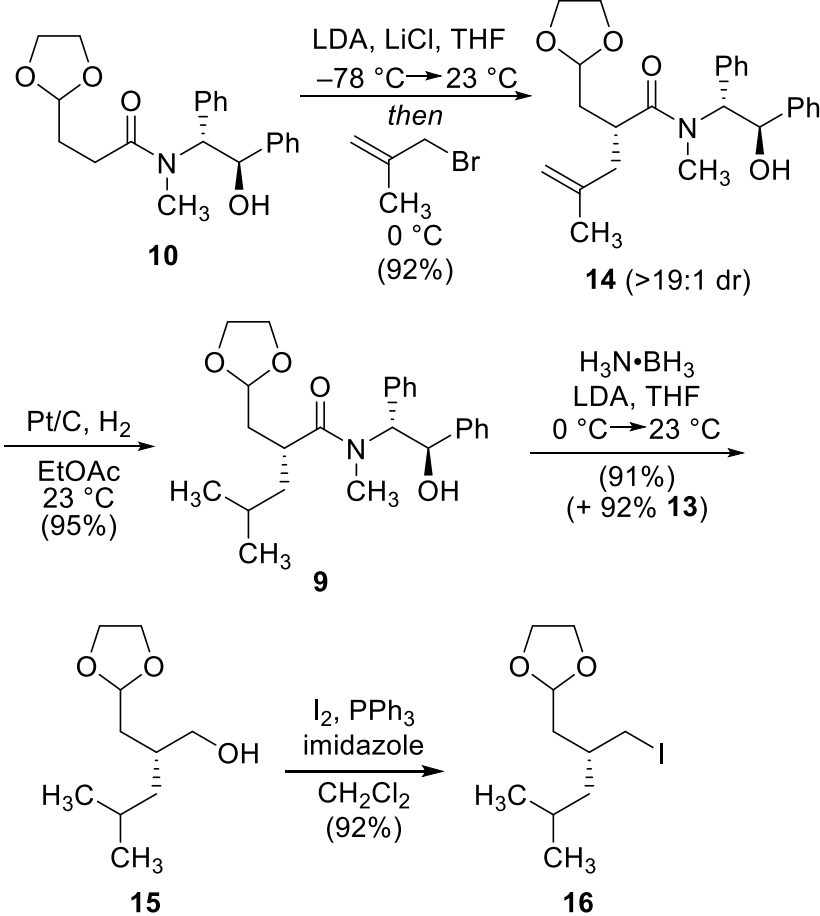
In a single experiment, we also evaluated the alkylation conditions recently reported by Collum and co-workers ${ }^{21}$ (sodium diisopropylamide as base at $-78{ }^{\circ} \mathrm{C}$ rather than $\mathrm{LiCl}-\mathrm{LDA}$ at $0{ }^{\circ} \mathrm{C}$ ) and found them to be effective as well as convenient, providing 14 in $83 \%$ yield $(287 \mathrm{mg}$ ) with $>19: 1 \mathrm{dr}$. The isobutenyl side chain of amide $\mathbf{1 4}$ was hydrogenated (Pt/C catalysis) in ethyl acetate as solvent to provide the saturated product $\mathbf{9}$ in $95 \%$ yield $(30.5 \mathrm{~g})$ as a thick, colorless oil. Reduction of $\mathbf{9}$ with lithium amidotrihydroborate ${ }^{22}$ provided the primary alcohol 15 in $91 \%$ yield $(12.5 \mathrm{~g})$, and $(R, R)$-pseudoephenamine (13) was recovered in $92 \%$ yield by a simple extractive isolation. Using the Mosher ester method ${ }^{23}$ we ascertained that the transformation of $\mathbf{9}$ to $\mathbf{1 5}$ had proceeded without detectable epimerization ( $\mathrm{dr}>19: 1)$. Exposure of alcohol 15 to a combination of iodine, triphenylphosphine, and imidazole under the usual conditions ${ }^{24}$ provided the desired primary iodide $\mathbf{1 6}$ in $92 \%$ yield (18.0 g) as a colorless oil.

Formation of Elaborated Zinc Reagent 8 and Negishi Coupling. In exploring methods to transform the primary iodide 16 into the elaborated organozinc reagent 8 we found that use of chlorotrimethylsilane and/or 1,2dibromoethane as metallic zinc activators ${ }^{25}$ was not easily reproduced on scales above a half-gram (Scheme 3 ). In contrast, when we employed freshly prepared $2 \%$ copper-zinc couple ${ }^{26}$ in lieu of zinc metal, we found that organozinc formation proceeded smoothly at $55^{\circ} \mathrm{C}$ (benzene- $N, N$-dimethylformamide (DMF) as solvent) and was easily reproduced on scales of as much as $10 \mathrm{~g}$ (larger scales were not attempted). Negishi coupling between the elaborated organozinc reagent $\mathbf{8}$ (formed in situ using $10.0 \mathrm{~g}$ of 16) and the vinyl triflate 7 (17.4 g, 1.1 equiv, prepared by slight modifications of literature procedures, ${ }^{15}$ see Supporting Information) in the presence of lithium chloride (1.5 equiv $)^{27}$ using $[1,1$ ' bis(diphenylphosphino)ferrocene]dichloropalladium (II), complex with dichloromethane $\left(\mathrm{PdCl}_{2}(\mathrm{dppf}) \cdot \mathrm{CH}_{2} \mathrm{Cl}_{2}\right)$ as catalyst (0.02 equiv) in benzene-DMF as solvent at $55^{\circ} \mathrm{C}$ afforded the coupled product $\mathbf{1 7}$ as a colorless oil in $57 \%$ yield $(9.5 \mathrm{~g})$

Scheme 3. Organozinc Formation and Negishi Coupling
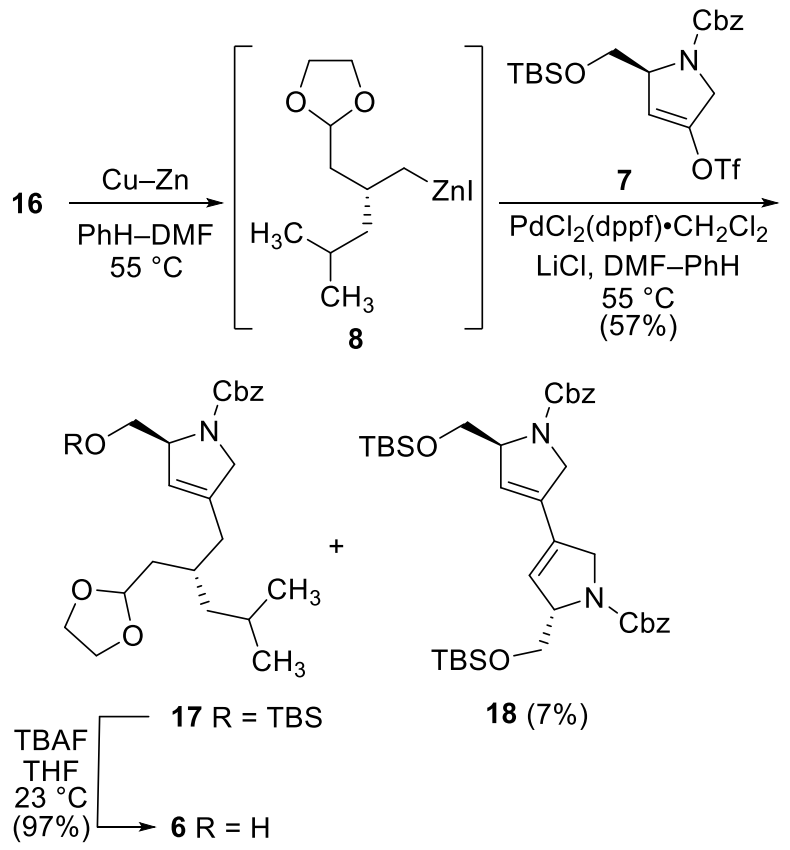

after extractive isolation and purification by flash-column chromatography. In separate chromatography fractions, we also recovered the vinyl triflate $7(38 \%)$ and a dienyl dimerization product (18, 7\% yield). Desilylation of coupling product 17 with tetra- $N$-butylammonium fluoride (TBAF) in THF at $23{ }^{\circ} \mathrm{C}$ gave rise to the key homoallylic alcohol intermediate 6 as a light-yellow oil (97\% yield, $7.2 \mathrm{~g}$ ).

Stereo- and Regioselective Hydration of Homoallylic Alcohol 6. The next and, as it transpired, greatest challenge in the synthetic route was to affect a suprafacial, antiMarkovnikov hydration of the alkene function within homoallylic alcohol 6 from its more hindered face - that which bears the hydroxymethyl group appendage (Scheme 4). The notion of using the homoallylic alcohol function to direct the addition was obvious but challenging to implement. Initially, we hoped that borane or another boron hydride reagent might first engage the hydroxyl group, evolving dihydrogen, and that the putative alkoxyboron hydride intermediate 19 might then undergo intramolecular hydroboration of the adjacent alkene. ${ }^{28}$ We recognized that the resulting [3.3.0]-bicyclooctane-type intermediate $\mathbf{2 0}$ would likely suffer from a degree of strain, but we hoped that this might be mitigated by proximity. In the event, it was not, for only the diol arising from addition to the less hindered face of the alkene (i.e. 21) was obtained after treatment with alkaline peroxide. Addition of a solution of borane THF complex to alcohol $\mathbf{6}$ led to instantaneous evolution of gas, certainly dihydrogen, suggesting that the alkoxyboron hydride intermediate $\mathbf{1 9}$ had likely formed, but intermolecular hydroboration of the less hindered face of the alkene was apparently faster than the desired course of reaction. ${ }^{29}$ Attempts to induce the desired transformation using equimolar quantities of borane THF complex at elevated temperatures, as well as exploration of a number of other boron hydride reagents (thexylborane, chloroborane, to name two) were not successful, and led to the recovery of starting material or to the formation of the undesired diol 21 (see Supporting Information). When exposed to the species arising from the combination of borane dimethyl sulfide complex and trifluoromethanesulfonic acid, 6 was observed to undergo reductive opening of the acetal protective group. ${ }^{30}$ After much additional experimentation not detailed here, we turned our focus to an alternative strategy to accomplish the desired transformation.

Scheme 4. An Attempt to Achieve a Directed, Intramolecular Hydroboration Reaction

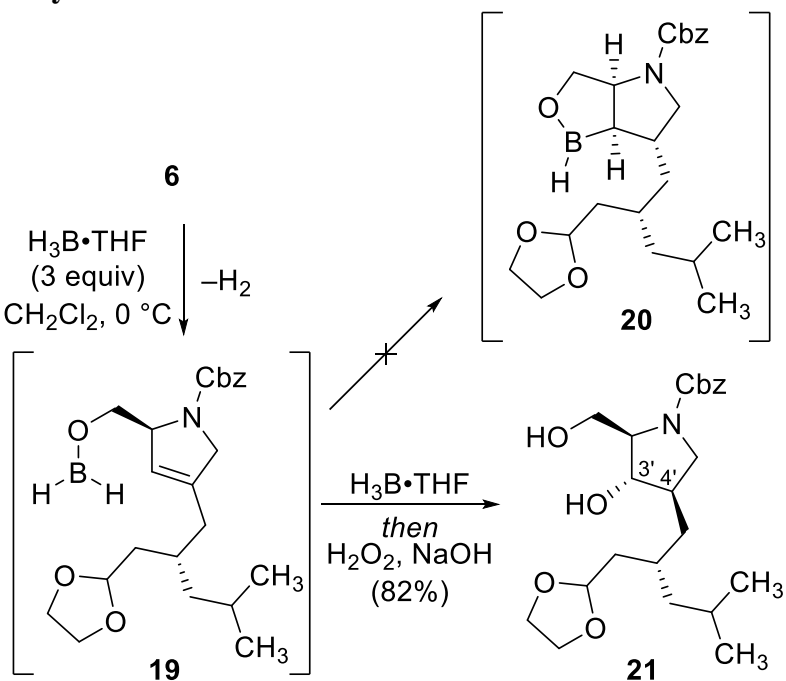




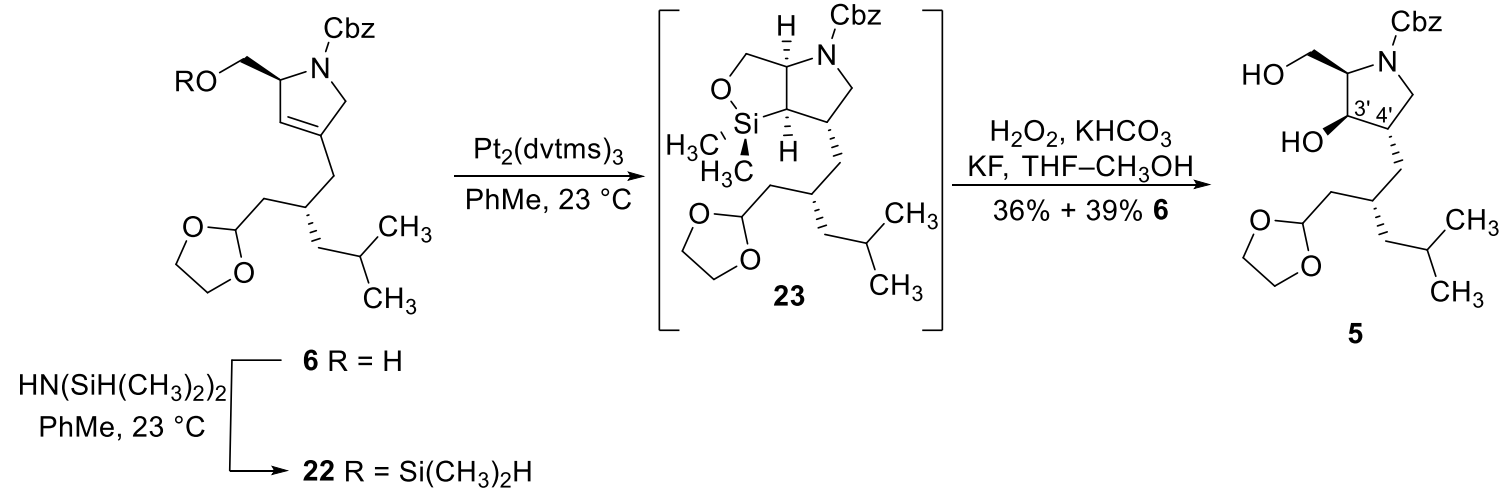

We turned instead to the strategy of intramolecular hydrosilylation followed by $\mathrm{C}-\mathrm{Si}$ bond oxidation, pioneered by Tamao and Ito. $^{31}$ In an early experiment, we exposed homoallylic alcohol 6 to an excess of 1,1,3,3,tetramethyldisilazane (4 equiv) in toluene at $23{ }^{\circ} \mathrm{C}$, and concentration to dryness under vacuum afforded the crude dimethylsilyl ether 22 (Scheme 5). This intermediate was then treated directly with Karstedt's catalyst (platinum-1,3-divinyl1,1,3,3-tetramethyldisiloxane complex, $\left.\mathrm{Pt}_{2}(\mathrm{dvtms})_{3}\right)$ in toluene at $23{ }^{\circ} \mathrm{C}$ to form the putative oxasilacycle 23 , in addition to other unidentified byproducts, and the crude mixture was subjected to alkaline peroxide in the work-up. After purification, we obtained the desired diol $\mathbf{5}$ in $36 \%$ yield. We also recovered $39 \%$ of the homoallylic alcohol $\mathbf{6}$, which we believe arises from a competing dimerization of the dimethylsilyl ether 22, which hydrolyzes to $\mathbf{6}$ upon work-up. Attempts to improve the yield of this transformation by using different transitionmetal catalysts (e.g., $[\mathrm{Rh}(\mathrm{cod}) \mathrm{Cl}]_{2}, \mathrm{Pt}\left(\mathrm{PPh}_{3}\right)_{4}$, and a platinum$N$-heterocyclic carbene catalyst ${ }^{32}$ ) or by slow addition of the silyl ether to a solution of the catalyst were not successful (see Supporting Information).

We then explored modifying the substituents on the silicon atom. Di-tert-butylsilyl, di-mesitylsilyl, and di-orthotolylsilyl ethers proved to be unreactive under a variety of conditions, and the diisopropylsilyl ether proved similar to the dimethylsilyl ether in terms of the final yield of $\mathbf{5}$. Among the silyl ethers investigated, the diphenylsilyl ether was found to be optimal. In addition, intermediates and by-products of the diphenylsilyl ether were found to be more stable than those of the dimethylsilyl ether, permitting their isolation and characterization (see Supporting Information). After additional experimentation, we found that replacement of toluene as solvent with THF improved the yield and provided a process that could be used to generate multi-gram quantities of $\mathbf{5}$.

Thus, the diphenylsilyl ether derived from alcohol $\mathbf{6}$ was prepared by its reaction with commercially available chlorodiphenylsilane in ethyl ether with triethylamine as a base (Scheme 6). After removal of the resulting triethylammonium chloride precipitate by filtration, the solution was thoroughly dried under vacuum to provide the diphenylsilyl ether as a thick colorless oil. In the optimized intramolecular hydrosilylation process, a dilute $(0.025 \mathrm{M})$ solution of the crude diphenylsilyl ether in THF at reflux was treated with a catalytic amount of Karstedt's catalyst (ca. 0.01 equiv). After consumption of the starting silyl ether $(3.5 \mathrm{~h})$, the crude mixture was cooled and directly subjected to Tamao-Fleming oxidation conditions, providing after purification by flash-column chro- matography, the diol $\mathbf{5}$ as a colorless oil which solidified upon standing $(4.3 \mathrm{~g}, 58 \%)$.

Scheme 6. Improved Hydrosilylation-Oxidation Conditions

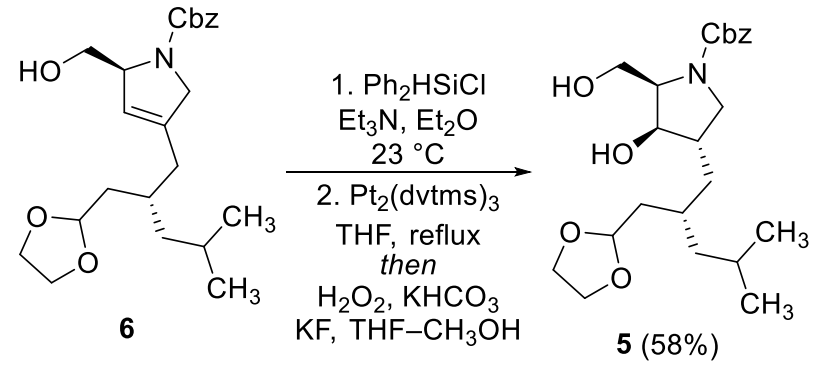

Oxepane Formation and Completion of the Synthesis. With multi-gram quantities of diol $\mathbf{5}$ in hand we turned to formation of the oxepane ring of $\mathbf{4}$ by a trans-acetalizationreduction sequence. In an initial experiment, the diol 5 was transformed into a 9:1 mixture of C9'-epimeric methoxy oxepane acetals 24 (stereochemistry of the major isomer not determined) upon exposure to methanol in the presence of $p$ toluenesulfonic acid monohydrate $\left(p-\mathrm{TSA} \cdot \mathrm{H}_{2} \mathrm{O}\right)$ at reflux (74\% yield after isolation and purification by flash-column

Scheme 7. Synthesis of Oxepane 25 by Reductive Transacetalization via a Methoxy Acetal

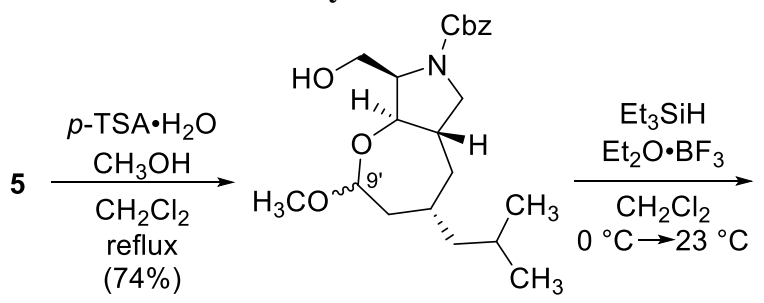

$24\left(9: 1 \mathrm{dr}\right.$ at $\left.\mathrm{C9}^{\prime}\right)$
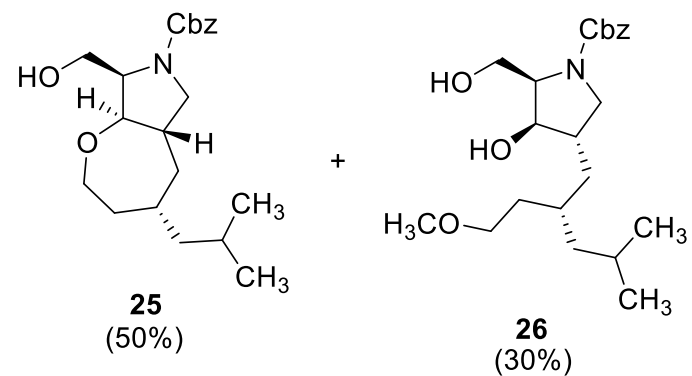
chromatography) (Scheme 7). When a solution of this mixture was treated with triethylsilane and boron trifluoride etherate at $0{ }^{\circ} \mathrm{C}$ and warmed to $23{ }^{\circ} \mathrm{C}$, the desired oxepane 25 was obtained in $50 \%$ yield. Isolated from separate chromatography fractions was the methyl ether by-product $\mathbf{2 6}$ (30\%), which must certainly arise from the alternative oxocarbenium ion formation that leads to ring-opening.

By replacing methanol with 1,1,1,3,3,3hexafluoroisopropanol (HFIP) to form mixed acetal 27 (single diastereomer, stereochemistry not determined), ring opening during the reduction step was suppressed, and oxepane $\mathbf{2 5}$ was isolated in $51 \%$ yield by a parallel two-step process (Scheme 8). The triol $\mathbf{2 8}$ was also observed as a side product in this reaction, suggesting that oxocarbenium capture by adventitious moisture may have been an issue.

\section{Scheme 8. An Improved Reductive Transacetalization Se-} quence

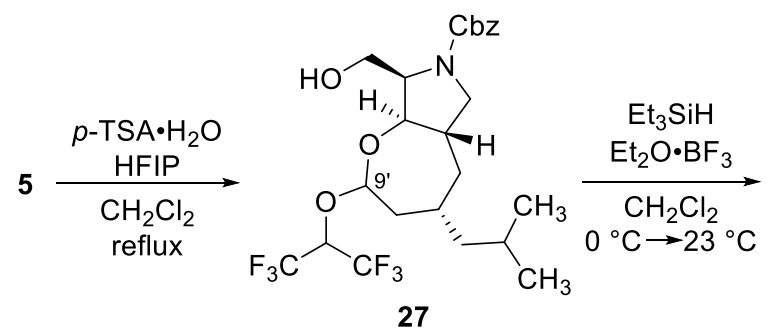

(single diastereomer)

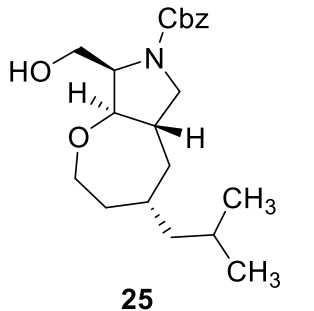

(51\%, 2 steps)

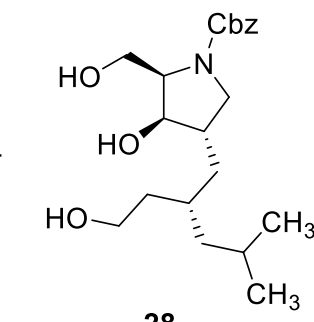

28
An improved, single-operation process was developed, one in which the diol 5 was held at reflux in a mixed solvent of dichloromethane and HFIP in the presence of $p$ TSA $\cdot \mathrm{H}_{2} \mathrm{O}$ (1.7 equiv) and freshly activated $3 \AA$ molecular sieves (MS) (Scheme 9). Subsequent addition of triethylsilane ( 8 equiv) and a second portion of $p$-TSA $\cdot \mathrm{H}_{2} \mathrm{O}$ (1.7 equiv) to the refluxing mixture with brief further reflux gave rise to oxepane 25 in $76 \%$ yield $(2.4 \mathrm{~g})$, which was purified by extractive workup and flash-column chromatography. The undesired triol $\mathbf{2 8}$ was isolated separately as a side product (8\%).

Oxidation of the primary alcohol function of oxepane 25 to a carboxyl group was achieved by a conventional twostep sequence of Dess-Martin periodinane oxidation to form the corresponding aldehyde, followed immediately by oxidation with sodium chlorite. ${ }^{33}$ The key carboxylic acid subtarget 4 was thus obtained in $92 \%$ yield over the two-step sequence (2.2 g). Coupling of carboxylic acid 4 with (7S)-7-deoxychloro methylthiolincosamine (7-Cl-MTL, 29) ${ }^{34}$ was best achieved using 3-(diethoxyphosphoryloxy)-1,2,3-benzotriazin-4(3H)one $(\mathrm{DEPBT})^{35}$ as the coupling reagent and $\mathrm{N}, \mathrm{N}$ diisopropylethylamine as base with DMF as solvent at $23{ }^{\circ} \mathrm{C}$. While other reagents such as HATU were also effective for this coupling, DEPBT allowed for the most facile purification protocol. After isolation by flash-column chromatography, the amide coupling product $\mathbf{3 0}$ was obtained as a white powder in
$82 \%$ yield ( $2.8 \mathrm{~g})$. No diastereomer resulting from epimerization at C2' was observed after this coupling. To complete the synthesis of iboxamycin (3), all that remained was to cleave the $N$-benzyloxycarbonyl protective group. For this, we employed a full equivalent of $10 \%$ palladium on carbon (catalyst poisoning by the methylthio function was believed to be an issue) under $1 \mathrm{~atm}$ of dihydrogen in THF as solvent at $23{ }^{\circ} \mathrm{C}$ (5 h). Flash-column chromatographic purification using $1 \%$ ammonium hydroxide in the eluent afforded the pure, freebase form of iboxamycin (3) in $81 \%$ yield (1.5 g) as a white powder. Prior to biological evaluation in vivo, this material was recrystallized from absolute ethanol to provide iboxamycin as fine white needles (first crop, 78\% recovery, mp 205$206^{\circ} \mathrm{C}$ ). Confirmation of all stereochemistry and structural details of iboxamycin was revealed by single-crystal X-ray analysis (CCDC \# 1949345) of a sample obtained after two consecutive recrystallizations from absolute ethanol.

We prepared several salts of iboxamycin (3), as well as a 2-phosphate ester prodrug for galenic evaluation. The preparation and characterization of these derivatives is described in the Supporting Information.

Scheme 9. Completion of the Synthesis
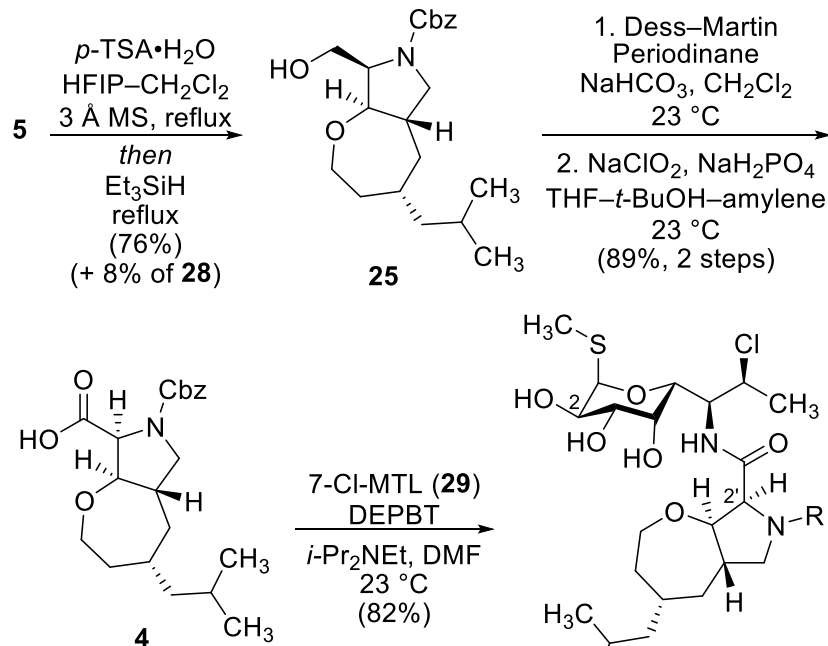

25

$(89 \%, 2$ steps $)$
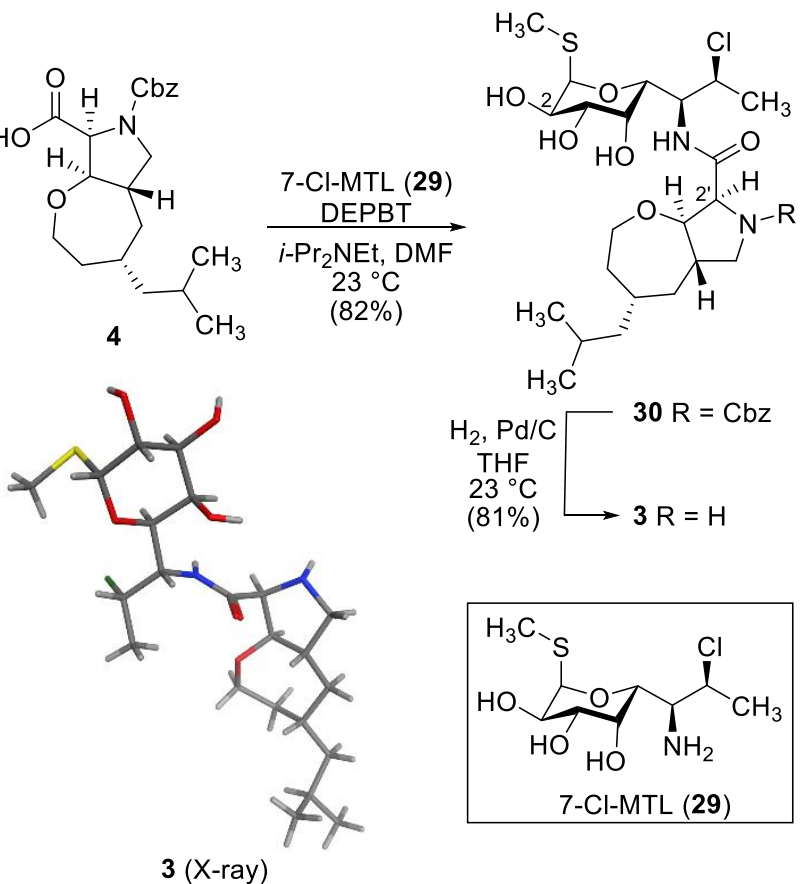

\section{CONCLUSION}

In summary, we have developed a convergent, stereoselective, and potentially scalable synthesis of iboxamycin (3), proceeding in $6.7 \%$ yield over 15 steps from the commercially available alkyl bromide $\mathbf{1 1}$. Key steps include a Negishi coupling involving the elaborated organozinc reagent $\mathbf{8}$ and vinyl triflate $\mathbf{7}$, a regio- and stereoselective olefin hydration of 
homoallylic alcohol $\mathbf{6}$ by an intramolecular hydrosilylation reaction followed by carbon-silicon bond oxidation, and a single-operation construction of the oxepane ring by transacetalization-reduction of diol $\mathbf{5}$. The component-based nature of the route $(\mathbf{7}, \mathbf{8}, \mathbf{2 9})$ makes fragment substitution quite feasible, and thus the route should provide a means to prepare a large number of additional analogs. The material furnished in these studies has permitted extensive in vivo analysis of iboxamycin (3) in murine infection models as well as other biological studies that would have been infeasible otherwise. ${ }^{13}$

\section{ASSOCIATED CONTENT}

\section{Supporting Information}

The Supporting Information is available free of charge on the ACS Publications website at DOI:

Detailed experimental procedures, supplementary tables, and all NMR characterization data (PDF)

X-ray data for iboxamycin (3) (CIF)

\section{AUTHOR INFORMATION}

\section{Corresponding Author}

Andrew G. Myers - Department of Chemistry and Chemical Biology, Harvard University, Cambridge, Massachusetts 02138, United States; Email: myers@chem.harvard.edu

\section{Authors}

Jeremy D. Mason - Department of Chemistry and Chemical Biology, Harvard University, Cambridge, Massachusetts 02138, United States; orcid.org/0000-0002-1039-0773

Daniel W. Terwilliger - Department of Chemistry and Chemical Biology, Harvard University, Cambridge, Massachusetts 02138, United States; orcid.org/0000-00028266-207X

Aditya R. Pote - Department of Chemistry and Chemical Biology, Harvard University, Cambridge, Massachusetts 02138, United States; orcid.org/0000-0001-8703-5190

\section{Notes}

A.G.M. has filed international patent applications WO/2019/032936 and WO/2019/032956 'Lincosamide Antibiotics and Uses Thereof'.

\section{ACKNOWLEDGEMENTS}

We gratefully acknowledge support from the LEO Foundation (grant LF18006).

We thank Dr. Shao-Liang Zheng for his help with the X-ray data collection and structure determination for iboxamycin (3). We also acknowledge Drs. Matthew M. Mitcheltree, Ioana Moga, and Katherine J. Silvestre for their work on the development of an improved synthesis of 7-Cl-MTL (29) from lincomycin.

\section{REFERENCES}

(1) For X-ray co-crystal structures of clindamycin bound to bacterial ribosomes see: (a) Schlünzen, F.; Zarlvach, R.; Harms, J.; Bashan, A.; Tocilj, A.; Albrecht, R. Yonath, A.; Franceschi, F. Structural Basis for the Interaction of Antibiotics with the Peptidyl Transferase Centre in Eubacteria. Nature 2001, 413, 814-821. (b) Tu, D.; Blaha, G.; Moore, P. B.; Steitz, T. A. Structures of MLS ${ }_{B}$ K Antibiotics Bound to Mutated Large Ribosomal Subunits Provide a Structural Explanation for Resistance. Cell 2005, 121, 257-270. (c) Dunkle, J. A.; Xiong, L.; Mankin, A. S.; Cate, J. H. D. Structures of the Escherichia coli Ribosome with Antibiotics Bound Near the Peptidyl Transferase Center Explain Spectra of Drug Action. Proc. Nat. Acad. Sci. U. S. A. 2010, 107, 17152-17157.

(2) Mason, D. J.; Dietz, A.; DeBoer, C. Lincomycin, a New Antibiotic. I. Discovery and Biological Properties. Antimicrob. Agents Chemother. (1961-1970) 1963, 554-559.

(3) Magerlein, B. J.; Birkenmeyer, R. D.; Kagan, F. Chemical Modification of Lincomycin. Antimicrob. Agents Chemother. (1961-1970) 1966, 727-736. (b) Magerlein, B. J.; Kagan, F. Lincomycin. XI. Synthesis and Structure of Clindamycin. A Potent Antibacterial Agent. $J$. Med. Chem. 1970, 13, 616-619.

(4) Obonyo, C. O.; Juma, E. A. Clindamycin Plus Quinine for Treating Uncomplicated falciparum Malaria: A Systemic Review and Meta-Analysis. Malaria J. 2012, 11, 2.

(5) Brook, I.; Lewis, M. A. O.; Sándor, G. K. B.; Jeffcoat, M.; Samaranayake, L. P.; Rojas, J. V. Clindamycin in Denstistry: More than Just Effective Prophylaxis for Endocarditis? Oral Surg., Oral Med., Oral Pathol., Oral Radiol., Endod. 2005, 100, 550-558.

(6) Fraimow, H. S. Systemic Antimicrobial Therapy in Osteomyelitis. Sem. In Plast. Surg. 2009, 23, 90-99.

(7) (a) Simonart, T.; Dramaix, M. Treatment of Acne with Topical Antibiotics: Lessons from Clinical Studies. Br. J. Dermatol. 2005, 153, 395-403. (b) Del Rosso, J. Q.; Schmidt, N. F. A Review of the Anti-Inflammatory Properties of Clindamycin in the Treatment of Acne Vulgaris. Cutis 2010, 85, 15-24.

(8) (a) Deshpande, A.; Pasupuleti, V.; Thota, P.; Pant, C.; Rolston, D. D. K.; Sferra, T. J.; Hernandez, A. V.; Donskey, C. J. Communityassociated Clostridium difficile Infection and Antibiotics: A MetaAnalysis. J. Antimicrob. Chemother. 2013, 68, 1951-1961. (b) Brown, K. A.; Khanafer, N.; Daneman, N.; Fisman, D. N. MetaAnalysis of Antibiotics and the Risk of Community-Associated Clostridium difficile Infection. Antimicrob. Agents Chemother. 2013, 57, 2326-2332. (c) Vardakas, K. Z.; Trigkidis, K. K.; Boukouvala, E.; Falagas, M. E. Clostridium difficile Infection Following Systemic Antibiotic Administration in Randomised Controlled Trials: A Systemic Review and Meta-Analysis. Int. J. Antimicrob. Agents 2013, 48, $1-10$.

(9) (a) U. S. Centers for Disease Control and Prevention. Antibiotic Resistance Threats in the United States 2019. Retrieved from https://www.cdc.gov/drugresistance/biggest-threats.html. (b) World Health Organization. Global Priority List of Antibiotic-Resistant Bacteria to Guide Research, Discovery, and Development of New Antibiotics. Retrieved from https://www.who.int/medicines/publications/WHO-PPL-

Short_Summary_25Feb-ET_NM_WHO.pdf.

(10) (a) For a summary of work by Upjohn prior to 1971: Magerlein, B. J. Modification of Lincomycin. Adv. Appl. Microbiol. 1971, 14, 185-229. For selected works by Upjohn appearing after 1971: (b) Bannister, B. Modifications of Lincomycin Involving the Carboxydrate Portion. Part I. The 2-O-Methyl and 2-Dexoy-analogues. $J$. Chem. Soc., Perkin Trans. 1 1972, 3025-3030. (c) Bannister, B. Modifications of Lincomycin Involving the Carbohydrate Portion. Part II. Analogues with D-Gluco- and D-Ido-stereochemistry. J. Chem. Soc., Perkin Trans. 1 1972, 3031-3036. (d) Birkenmeyer, R. D.; Kroll, S. J.; Lewis, C.; Stern, K. F.; Zurenko, G. E. Synthesis and Antimicrobial Activity of Clindamycin Analogs: Pirlimycin, a Potent Antibacterial Agent. J. Med. Chem. 1984, 27, 216-223. For works published by academic groups: (e) Hanessian, S.; Sato, K.; Liak, T. J.; Danh, N.; Dixit, D. Cheney, B. V. "Quantamycin" - A Computer-Simulated 
New-Generation Inhibitor of Bacterial Ribosome Binding. J. Am. Chem. Soc. 1984, 106, 6114-6115. (f) Collin, M. -P.; Hobbie, S. N.; Böttger, E. C.; Vasella, A. Synthesis of 1,2,3-Triazole Analogues of Lincomycin. Helv. Chim. Acta. 2008, 91, 1938-1948. (g) Collin, M. P.; Hobbie, S. N.; Böttger, E. C.; Vasella, A. Synthesis and Evaluation of $S$ - and $C(1)$-Substituted Analogues of Lincomycin. Helv. Chim. Acta. 2009, 92, 230-243. For a summary of work by Vicuron Pharmaceuticals: (h) Lewis, J. G.; Anandan, S. K.; O’Dowd, H.; Gordeev, M. F.; Li, L. Lincomycin derivatives possessing antibacterial activity. US Patent 7,361,743 B2, April 22, 2008. For selected works by Meiji Seika Pharma Co.: (i) Umemura, E.; Wakiyama, Y.; Kumura, K.; Ueda, K.; Masaki, S.; Watanabe, T.; Yamamoto, M.; Hirai, Y.; Fushimi, H.; Yoshida, T.; Ajito, K. Synthesis of Novel Lincomycin Derivatives and their In Vitro Antibacterial Activities. J. Antibiot. 2013, 66, 195-198 (j) Wakiyama, Y.; Kumura, K.; Umemura, E.; Ueda, K.; Masaki, S.; Kumura, M.; Fushimi, H.; Ajito, K. Synthesis and Structure-Activity Relationships of Novel Lincomycin Derivatives. Part 1. Newly Generated Antibacterial Activities Against GramPositive Bacteria with erm Gene by C-7 Modification. J. Antibiot. 2016, 69, 368-380. (k) Kumura, K.; Wakiyama, Y.; Ueda, K.; Umemura, E.; Watanabe, T.; Shitara, E.; Fushimi, H.; Yoshida, T.; Ajito, K. Synthesis and Antibacterial Activity of Novel Lincomycin Derivatives. I. Enhancement of Antibacterial Activities by Introduction of Substituted Azetidines. J. Antibiot. 2016, 69, 440-445. (1) Kumura, K.; Wakiyama, Y.; Ueda, K.; Umemura, E.; Watanabe, T.; Kumura, M.; Yoshida, T.; Ajito, K. Synthesis and Antibacterial Activity of Novel Lincomycin Derivatives. II. Exploring (7S)-7-(5-Aryl1,3,4-thiadiazol-2-yl-thio)-7-deoxylincomycin Derivatives. J. Antibiot. 2017, 70, 655-663. (m) Kumura, K.; Wakiyama, Y.; Ueda, K.; Umemura, E.; Watanabe, T.; Yamamoto, M.; Yoshida, T.; Ajito, K. Synthesis and Antibacterial Activity of Novel Lincomycin Derivatives. III. Optimization of a Phenyl Thiadiazole Moiety. J. Antibiot. 2018, 71, 104-112. (n) Wakiyama, Y.; Kumura, K.; Umemura, E.; Masaki, S.; Ueda, K.; Sato, Y.; Hirai, Y.; Hayashi, Y.; Ajito, K. Synthesis and Structure-Activity Relationships of Novel Lincomycin Derivatives Part 5: Optimization of Lincomycin Analogs Exhibiting Potent Antibacterial Activities by Chemical Modification of the 6and 7-Positions. J. Antibiot. 2018, 71, 298-317.

(11) (a) Mitcheltree, M. M. Ph. D. Thesis, Harvard University, 2018. (b) Mitcheltree, M. M.; Stevenson, J. W.; Pisipati, A.; Myers, A. G. A Practical, Component-Based Synthetic Route to Methylthiolincosamine Permitting Facile Northern-Half Diversification of Lincosamide Antibiotics. In Review.

(12) (a) Silvestre, K. J. Ph. D. Thesis, Harvard University, 2018. (b) Moga, I. Ph. D. Thesis, Harvard University, 2018.

(13) Mitcheltree, M. M.; Pisipati, A.; Syroegin, E. A.; Kilvestre, K. J.; Klepacki, D.; Mason, J. D.; Terwilliger, D. W.; Testolin, G.; Pote, A. R.; Wu, K.; Ladley, R. P.; Chatman, K.; Mankin, A. S.; Polikanov, Y. S.; Myers, A. G. A synthetic antibiotic scaffold effective against multidrug-resistant bacterial pathogens. In Review.

(14) (a) Negishi, E.; King. A. O.; Okukado, N. Selective CarbonCarbon Bond Formation via Transition Metal Catalysis. 3. A Highly Selective Synthesis of Unsymmetrical Biaryls and Diarylmethanes by the Nickel- or Palladium-Catalyzed Reaction of Aryl- and Benzylzinc Derivatives with Aryl Halides. J. Org. Chem. 1977, 42, 1821-1823. (b) Diner, C.; Organ, M. G. The Negishi Cross-Coupling Reaction. Organic Reactions 2019, 100, 1-62.

(15) (a) Antonow, D.; Kaliszczak, M.; Kang, G.-D.; Coffils, M.; Tiberghien, A. C.; Cooper, N.; Barata, T.; Heidelberger, S.; James, C. H.; Zloh, M.; Jenkins, T. C.; Reszka, A. P.; Neidle, S.; Guichard, S. M.; Jodrell, D. I.; Hartley, J. A.; Howard, P. W.; Thurston, D. E. Structure-Activity Relationships of Monomeric C2-Aryl Pyrrolo[2,1c] $[1,4]$ benzodiazepine (PBD) Antitumor Agents. J. Med. Chem. 2010, 53, 2927-2941. (b) Tiberghien, A. C.; von Bulow, C.; Barry, C.; Ge, H.; Noti, C.; Leiris, F. C.; McCormick, M.; Howard, P.; W.; Parker, J. S. Scale-up Synthesis of Tesirine. Org. Process Res. Dev. 2018, 22, $1241-1256$

(16) (a) Myers, A. G.; Yang, B. H.; Chen, H.; Gleason, J. L. Use of Pseudoephedrine as a Practical Chiral Auxiliary for Asymmetric Synthesis. J. Am. Chem. Soc. 1994, 116, 9361-9362. (b) Myers, A. G.; Yang, B. H.; Chen, H.; McKinstry, L.; Kopecky, D. J.; Gleason, J. L.
Pseudoephedrine as a Practical Chiral Auxiliary for the Synthesis of Highly Enantiometrically Enriched Carboxylic Acids, Alcohols, Aldehydes, and Ketones. J. Am. Chem. Soc. 1997, 119, 6496-6511. (c) Morales, M. R.; Mellem, K. T.; Myers, A. G. Pseudoephenamine: A Practical Chiral Auxiliary for Asymmetric Synthesis. Angew. Chem., Int. Ed. 2012, 51, 4568-4571.

(17) (a) Shea, K. J.; Wada, E. Synthesis and Chemistry of a Bridgehead Enol Lactone. J. Am. Chem. Soc. 1982, 104, 5715-5719. (b) Deuss, P. J.; Popa, G.; Botting, C. H.; Laan, W.; Kramer, P. C. J. Highly Efficient and Site-Selective Phosphane Modification of Proteins through Hydrazone Linkage: Development of Artificial Metalloenzymes. Angew. Chem., Int. Ed. 2010, 49, 5315-5317.

(18) Tilstam, U.; Weinmann, H. Activation of Mg Metal for Safe Formation of Grignard Reagents on Plant Scale. Org. Proc. Res. Dev. 2002, 6, 906-910.

(19) Hogan, P. C.; Chen, C. -L.; Mulvihill, K. M.; Lawrence, J. F.; Moorhead, E.; Rickmeier J.; Myers, A. G. Large-Scale Preparation of Key Building Blocks for the Manufacture of Fully Synthetic Macrolide Antibiotics. J. Antibiot. 2018, 71, 318-325.

(20) Chain, W. J.; Myers, A. G. A Convenient, NMR-Based Method for the Analysis of Diastereomeric Mixtures of Pseudoephedrine Amides. Org. Lett. 2007, 9, 335-357.

(21) Zhou, Y.; Keresztes, I.; MacMillan, S. N.; Collum, D. B. Disodium Salts of Pseudoephedrine-Derived Myers Enolates: Stereoselectivity and Mechanism of Alkylation. J. Am. Chem. Soc. 2019, 141, 16865-16876.

(22) (a) Myers, A. G.; Yang, B.; Kopecky, D. Lithium Amidotrihydroborate, a Powerful New Reductant. Transformation of Tertiary Amides to Primary Alcohols. Tetrahedron Lett. 1996, 37, 3623-3626. (b) Myers, A. G.; Yang, B. H.; Chen, H.; Kopecky, D. J. Asymmetric Synthesis of 1,3-Dialkyl-Substituted Carbon Chains of any Stereochemical Configuration by an Iterable Process. Synlett 1997, 457459.

(23) Dale, J. A.; Dull, D. L.; Mosher, H. S. $\alpha$-Methoxy- $\alpha-$ trifluoromethylphenylacetic Acid, a Versatile Reagent for the Determination of Enantiomeric Composition of Alcohols and Amines. $J$. Org. Chem. 1969, 34, 2543-2549.

(24) Lange, G. L.; Gottardo, C. Facile Conversion of Primary and Secondary Alcohols to Alkyl Iodides. Synth. Commun. 1990, 20, 1473-1479.

(25) (a) Erdik, E. Use of Activation Methods for Organozinc Reagents. Tetrahedron 1987, 43, 2203-2212. (b) Knochel, P.; Millot, P.; Rodriguez, A. L.; Tucker, C. E. Preparation and Applications of Functionalized Organozinc Compounds. Organic Reactions 2001, 58, 417-759.

(26) LeGoff, E. Cyclopropanes from an Easily Prepared, Highly Active Zinc-Copper Couple, Dibromomethane, and Olefins. J. Org. Chem. 1964, 29, 2048-2050.

(27) It should be noted that in the absence of $\mathrm{LiCl}$ the coupled product 17 was obtained in only $17 \%$ yield, along with $3 \%$ of diene $\mathbf{1 8}$. For background references regarding the importance of $\mathrm{LiCl}$ in palladiumcatalyzed cross couplings involving vinyl triflates see: (a) Scott, W. J.; Crisp, G. T.; Stille, J. K. Palladium-Catalyzed Coupling of Vinyl Triflates with Organostannanes. A Short Synthesis of Pleraplysillin-1. J. Am. Chem. Soc. 1984, 106, 4630-4632. (b) Scott, W. J.; Stille, J. K. Palladium-Catalyzed Coupling of Vinyl Triflates with Organostannanes. Synthetic and Mechanistic Studies. J. Am. Chem. Soc. 1986, 108, 3033-3040. (c) Eckert, P.; Sharif, S.; Organ, M. G. Salt to Taste: The Critical Roles Played by Inorganic Salts in Organozinc Formation and in the Negishi Reaction. Angew. Chem. Int. Ed. 2020, 59, doi.org/10.1002/anie.202010917.

(28) For examples of reported exocyclic hydroxymethyl-directed hydroborations see: (a) Nicolaou, K. C.; Liu, J. J.; Hwang, C. -K.; Dai, W. -M.; Guy, R. K. Synthesis of a Fully Functionalized $C D$ Ring System of Taxol. J. Chem. Soc., Chem. Commun. 1992, 1118-1120. (b) Yadav, J. S.; Sasmal, P. K. Diels-Alder Approach Towards the Stereocontrolled Construction of a Taxol ${ }^{\circledR}$ C Ring Fragment. Tetrahedron 1999, 55, 5185-5194.

(29) For examples of attempted hydroxyl-directed hydroborations that were reported as unsuccessful: (a) Heathcock, C. H.; Jarvi, E. T.; Rosen, T. Acyclic Stereoselection. 21. Synthesis of an Ionophore 
Synthon Having Four Asymmetric Carbons by Sequential Aldol Addition, Claisen Rearrangement and Hydroboration. Tetrahedron Lett. 1984, 25, 243-246. (b) Birtwistle, D. H.; Brown, J. M.; Foxton, M. W. Stereoselectivity in the Hybroboration of Chiral CyclohexaneDerived Allylic Alcohols. Tetrahedron Lett. 1986, 27, 4367-4370. (c) Smith, A. B., III; Yokoyama, Y.; Huryn, D. M.; Dunlap, N. K. Total Synthesis of (+)-Mikrolin. Tetrahedron Lett. 1987, 28, 3659-3662.

(30) Rarig, R.-A., F.; Scheideman, M.; Vedejs, E. Oxygen-Directed Intramolecular Hydroboration. J. Am. Chem. Soc. 2008, 130, 9182 9183.

(31) (a) Tamao, K.; Tanaka, T.; Nakajima, T.; Sumiya, R.; Arai, H.; Ito, Y. Silafunctional Compounds in Organic Synthesis. 30. Intramolecular Hydrosilation of Alkenyl Alcohols: A New Approach to the Regioselective synthesis of 1,2- and 1,3-Diols. Tetrahedron Lett. 1986, 27, 3377-3380. (b) Tamao, K.; Nakajima, T.; Sumiya, R.; Arai, H.; Higuchi, N.; Ito, Y. Stereocontrol in Intramolecular Hydrosilylation of Allyl and Homoallyl Alcohols: A New Approach to the Stereoselective Synthesis of 1,3-Diol Skeletons. J. Am. Chem. Soc. 1986, 108, 6090-6093. (c) Tamao, K.; Nakagawa, Y.; Arai, H.; Higuchi, N.; Ito, Y. Intramolecular Hydrosilation of $\alpha$-Hydroxy Enol Ethers: A New Highly Stereoselective Route to Polyhydroxylated Molecules. $J$. Am. Chem. Soc. 1988, 110, 3712-3714.

(32) Markó, I. E.; Stérin, S.; Buisine, O.; Mignani, G.; Branlard, P.; Tinant, B.; Declercq, J. -P. Selective and Efficient Platinum (0)Carbene Complexes as Hydrosilylation Catalysts. Science 2002, 298, 204-206.

(33) (a) Lindgren, B. O.; Nilsson, T.; Husebe, S.; Mikalsen, Ø.; Leander, K.; Swahn, C. -G. Preparation of Carboxylic Acids from Aldehydes (Including Hydroxylated Benzaldehydes) by Oxidation with Chlorite. Acta Chem. Scand. 1973, 27, 888-890. (b) Kraus, G. A.; Taschner, M. J. Model Studies for the Synthesis of Quassinoids. 1. Construction of the BCE Ring System. J. Org. Chem. 1980, 45, 11751176. (c) Kraus, G. A.; Roth, B. Synthetic Studies Toward Verrucarol. 2. Synthesis of the AB Ring System. J. Org. Chem. 1980, 45, 4825-4830

(33) 7-Cl-MTL (29) was prepared in multigram quantities in four steps starting from lincomycin by minor modifications of the reported procedure, See Supporting Information for details. Lewis, J. G.; Anandan, S. K.; O'Dowd, H.; Gordeev, M. F.; Li, L. Lincomycin derivatives possessing antibacterial activity. US Patent 7,361,743 B2, April 22, 2008.

(34) (a) Fan, C. -X.; Hao, X. -L.; Ye, Y. -H.; A Novel Organophosphorus Compound as a Coupling Reagent for Peptide Synthesis. Synth. Commun. 1996, 26, 1455-1460. (b) Li, H.; Jiang, X.; Ye, Y. h.; Fan, C.; Romoff, T.; Goodman, M. 3-(Diethoxyphosphoryloxy)1,2,3-benzotriazin-4(3H)-one (DEPBT): A New Coupling Reagent with Remarkable Resistance to Racemization. Org. Lett. 1999, 1, 9193.

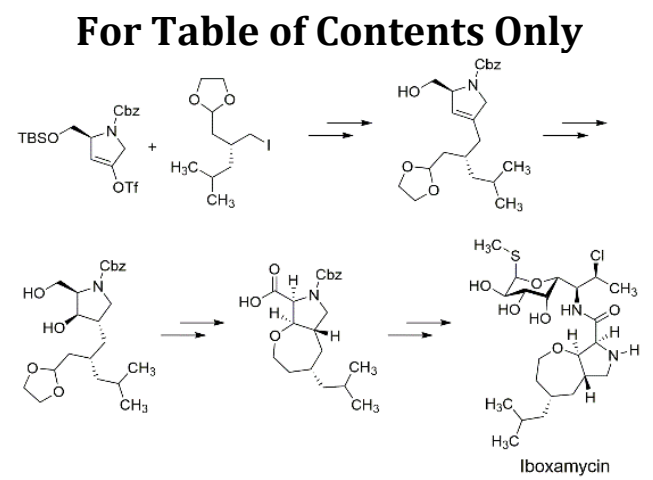

